\title{
CAPITAL GOODS FOR ENERGY DEVELOPMENT: Power Equipment for Developing Countries
}

\author{
Jyoti K. Parikh \\ International Institute for Applied Systems Analysis, Schloss Laxenburg, \\ Austria
}

\section{INTRODUCTION}

\subsection{Background}

Energy problems of the developing countries have three facets: large import bills for oil and oil products, scarcity of biomass for cooking, and import bills and investment required for energy development. While the first two are discussed often in the literature, the third, although of great concern to national governments and many aid agencies, needs to be analyzed in more detail. The magnitude of the third problem can be appreciated in light of the fact that in 1980, according to a World Bank estimate, roughly US\$34 billion were invested in the energy sector (1), of which US $\$ 25$ billion were used to import machinery or capital goods for energy development. 'These include a wide variety of goods, such as power machinery (e.g. turbines, generators, boilers, switch gears, and insulating cables) fossil fuel-related equipment (e.g. oil rigs, liquid pumps, gas pipes,

\footnotetext{
'The term "energy capital goods" in this paper signifies equipment necessary to set up new energy facilities or to complement existing ones. The term "energy facilities" or "energy supply industries" includes power plants (and their distribution facilities), refineries, oil wells, coal mines, windmills, bio-gas plants, and the like. "Power" essentially means electric power because that is the largest component. A small component of motive power may also be included, but most of it is used in the transport and industries sectors and not for energy facilities. Electric power is the rate at which electricity (a form of energy) is supplied. However, since capital goods required for electricity or power are the same, both terms are used interchangeably.
} 
and coal mining equipment), and handling machinery (e.g. excavators and cranes). These two figures can be compared with US $\$ 35$ billion for importing crude oil and US $\$ 10$ billion for oil products for the same year. It is interesting to compare them because both of them not only compete for foreign exchange but are partial substitutes for each other. That is, with more energy capital goods it may be possible to reduce oil imports. In 1980 , the developing countries claimed $12 \%$ of total world imports of crude oil, but had $30 \%$ to $60 \%$ (depending on the equipment) of the world imports of energy capital goods (2).

In 1983, however, imports of capital goods for electric power dropped to US\$15 billion, and the overall share of imports in the world market dropped from $33 \%$ in 1980 to $27 \%$. This may be attributed partly to the high exchange rate for US\$, low economic growth in the developing countries, and a reduction in foreign aid. While oil and oil products are required for servicing existing machinery and capital stock and hence for running the economy, energy capital goods generate new capacity to produce more energy, building up the economy. ${ }^{2}$

Electricity facilities form a basic infrastructure necessary for industrialization. For most developing countries, the ratio of the growth rate of electricity generation to that of GDP, averaging around 1.2, is higher than the ratio of the growth rate of energy consumption to that of GDP, averaging around 1.0 (Jankowski, 3). This is even more true after 1973, when, due to the rise in oil prices, the share of oil in total energy began to fall. The reasons are not difficult to find. On the supply side, electricity can be generated from any of several indigenous sources, e.g. hydropower, coal, gas, nuclear power, or geothermal power. On the demand side, it is a highly efficient and versatile form of energy that can be used in thermal and electrochemical processes and, through electromagnetic conversion, to drive rotating machinery. In the developing countries, it is increasingly substituted for human energy, noncommercial energy, and energy from fossil fuels-especially oil. Thus, in spite of high oil prices, electricity growth rates have continued to be high, although not as high as they were before 1973. Since all countries require electricity, the question of importing and/or manufacturing of equipment related to electricity concerns all developing countries.

The procurement of electric power equipment by developing countries concerns not only them alone, but also the developed countries. Of the total world trade of about US $\$ 45$ billion, the share of developing countries was nearly $32 \%$ in 1983 . Their share in world trade rose from $27 \%$ in 1970

\footnotetext{
${ }^{2}$ Even so, the comparison is valid because what we are comparing here are streams of annual commitments of foreign exchange and not investment per unit energy.
} 
to nearly $34 \%$ in 1980 . (While this trend of rising shares was interrupted in 1983, informal inquiries to manufacturers from developed countries indicate that during the remaining years of the 1980s, the highest share of new power plants is expected to be in the developing countries.)

To reduce foreign exchange payments and to increase self-reliance, the developing countries need to increase their efforts in domestic manufacturing of electric power equipment in whatever modest way is possible. Behind the goals of indigenization lies the basic desire for participation in the process of industrialization. Every developing country, small or big, oil exporting or oil importing, island or land-locked, recognizes the need for industrialization, although patterns of industrialization may differ. Electricity is an essential component of industrialization. However, the priority for manufacturing electric equipment depends on the extent of electricity generation required, patterns of industrialization, and the priorities of other sectors that may claim skilled personnel, financial resources, and other necessities, in addition to the costs of inputs and the prices of outputs nationally and internationally.

The present paper aims to identify these conditions for different groups of developing countries, for different levels of technological complexity, and for different modes of procurement, whether imports or manufacturing.

\section{RECENT TRENDS IN ENERGY CONSUMPTION PATTERNS AND IMPORTS OF CAPITAL GOODS: AN OVERVIEW AT THE WORLD REGIONAL LEVEL}

\subsection{Energy Consumption Patterns}

Although this paper deals with energy supply rather than energy demand, a short discussion of the recent structural changes in demand patterns is essential to estimate the requirements for capital goods. In particular, recent changes in the growth rates of the production and consumption of energy as a whole and of its two important elements, oil and electricity, as well as changes in the energy mix, are the most relevant indicators.

\subsubsection{STRUCTURAL CHANGES IN ENERGY CONSUMPTION PATTERNS AND} THEIR IMPLICATIONS Two major changes took place after each rise of oil prices, in 1973 and 1979 :

1. reductions in energy consumption growth rates;

2. changes in the energy mix, i.e. a reduced share for oil.

The first change was the most important. In the 1950s and 1960s energy consumption growth rates increased, but in the 1970s, especially after 
1973, growth slowed. Some of the recent statistics on this trend are summarized in Table 1. The changes that took place after the 1979 price rise are of special interest. During 1979-1981, the world experienced negative growth rates in the consumption and production of both energy and oil.

Table 1 shows that the growth rate of energy consumption in the world, which was $4.61 \%$ in $1965-1973$, fell to $-0.93 \%$ in $1979-1981$, as indicated in (4). The growth rate for the developing countries in 1979-1981 was $3.01 \%$ as compared to $7.84 \%$ in $1965-1973$. The growth rates of oil consumption relative to the growth rates for total commercial energy consumption for all economies fell after 1973. In the developing market economies, oil consumption growth rates declined from $8.0 \%$ in 19651973 to $2.2 \%$ in $1979-1981$. Shares of other energy sources, such as coal, gas, and hydropower, were correspondingly higher.

Interestingly, even though the share of electricity in total primary energy is no more than $10 \%-20 \%$ of total energy, electricity claims a large share of capital and capital goods requirements for the energy sector. In 19801985 Bangladesh (5) planned to spend $14.5 \%$ of its development expenditures on energy, of which $69 \%$ was for electricity. In Kenya (6), $10.5 \%$ of capital formation in 1983 was in the energy sector, most of which was

Table 1 Production and consumption of commercial energy and oil (average annual growth rates, percent per year)

\begin{tabular}{|c|c|c|c|c|c|c|}
\hline & & Produc & ion & & onsump & \\
\hline $\begin{array}{l}\text { Country } \\
\text { groups }\end{array}$ & $\begin{array}{l}\text { Time } \\
\text { period }\end{array}$ & $\begin{array}{l}\text { Commercial } \\
\text { energy }\end{array}$ & Oil & $\begin{array}{c}\text { Commercial } \\
\text { energy }\end{array}$ & Oil & Electricity \\
\hline $\begin{array}{l}\text { Developed market } \\
\text { economies }^{\mathbf{a}}\end{array}$ & $\begin{array}{l}1965-1973 \\
1973-1979\end{array}$ & $\begin{array}{l}2.85 \\
1.29\end{array}$ & $\begin{array}{l}3.71 \\
0.96\end{array}$ & $\begin{array}{l}4.43 \\
1.12\end{array}$ & $\begin{array}{l}6.53 \\
0.40\end{array}$ & $\begin{array}{l}7.3 \\
3.4\end{array}$ \\
\hline $\begin{array}{l}\text { Centrally planned } \\
\text { economies }^{\mathrm{b}}\end{array}$ & $\begin{array}{l}1965-1973 \\
1973-1979\end{array}$ & $\begin{array}{l}4.16 \\
5.27\end{array}$ & $\begin{array}{r}10.16 \\
6.16\end{array}$ & $\begin{array}{l}4.41 \\
4.88\end{array}$ & $\begin{array}{l}7.90 \\
5.15\end{array}$ & $\begin{array}{l}7.4 \\
6.5\end{array}$ \\
\hline $\begin{array}{l}\text { Developing market } \\
\text { economies }^{c}\end{array}$ & $\begin{array}{l}1965-1973 \\
1973-1979 \\
1979-1981\end{array}$ & $\begin{array}{r}9.67 \\
1.46 \\
-6.41\end{array}$ & $\begin{array}{r}9.97 \\
0.93 \\
-10.41\end{array}$ & $\begin{array}{l}7.84 \\
5.85 \\
3.01\end{array}$ & $\begin{array}{l}8.00 \\
5.89 \\
2.19\end{array}$ & $\begin{array}{r}10.3 \\
9.0 \\
5.6\end{array}$ \\
\hline World & $\begin{array}{c}1965-1973 \\
1973-1979 \\
1979-1981\end{array}$ & $\begin{array}{r}5.44 \\
2.55 \\
-1.87\end{array}$ & $\begin{array}{r}7.89 \\
1.95 \\
-5.30\end{array}$ & $\begin{array}{r}4.61 \\
2.69 \\
-0.93\end{array}$ & $\begin{array}{r}6.92 \\
2.04 \\
-4.04\end{array}$ & $\begin{array}{l}7.6 \\
4.6 \\
2.4\end{array}$ \\
\hline
\end{tabular}

Source: United Nations Yearbook of World Energy Statistics (1974), (1979), and (1981).

a Market economies: including countries of North America, Western Europe, Japan, and Oceania.

${ }^{\mathrm{b}}$ Including countries of Eastern Europe, USSR, People's Republic of China, and East Asia.

${ }^{\mathrm{C}}$ Developing market economies of Asia, Africa, and Latin America.

There has been a change in the reporting system of the energy statistics in 1981, and the subtotals for each group of countries are not readily available. The author has added subtotals only for the developing countries. There may be slight inconsistencies with the previous years due to differences in the coverage of small countries. This may have effects on growth rates of 1979-1981. However, the general pattern indicated here is not likely to be altered drastically by these minor changes. 
in the power sector. In India, according to the Sixth Five-Year Plan 1980 85 (7), $27 \%$ of the expenditure was for the energy sector, and $70 \%$ of that was for the power sector. The desirability of such emphasis on the power sector in energy plans has been questioned recently (World Bank, 8), and the developing countries have been encouraged to invest in new and renewable energy resources. This change will no doubt be welcome if the projects are given a high priority. However, the predominance of the power sector in the plans of the developing countries is due to many causes, and that sector will continue to claim a major share of energy investment.

The annual growth rates of electricity consumption have decreased from $10 \%$ in Africa and the Far East and 14\% in Latin America in the 1960s to $8 \%$ and $10 \%$, respectively, in the 1970 s (J. Parikh, 9). In spite of high oil prices, high growth of electricity consumption (of about $6 \%$ ) is expected to continue in the 1980s because of the large areas remaining yet to be electrified and very low levels of per capita electricity consumption prevalent in the developing countries.

Table 2 shows the shares of the developing countries in the world market

Table 2 Changes in imports of capital goods (1980)

\begin{tabular}{|c|c|c|c|c|c|c|c|}
\hline \multirow[b]{2}{*}{$\begin{array}{c}\text { Item } \\
\text { description }\end{array}$} & \multirow[b]{2}{*}{$\begin{array}{l}\text { SITC } \\
\text { No. }\end{array}$} & \multirow{2}{*}{$\begin{array}{c}\text { Imports } \\
\text { in } 10^{6} \$ \\
1980^{b}\end{array}$} & \multirow[b]{2}{*}{ Year } & \multicolumn{4}{|c|}{ Shares of importers } \\
\hline & & & & $\begin{array}{l}\text { Developing } \\
\text { countries }^{c}\end{array}$ & Africa & $\begin{array}{l}\text { Latin } \\
\text { America }\end{array}$ & Asia \\
\hline \multirow[t]{2}{*}{ Steam turbines ${ }^{\mathrm{a}}$} & 712 & & 1971 & 22.7 & 1.1 & 8.5 & 13.0 \\
\hline & & 1110 & 1979 & 35.5 & 2.1 & 8.9 & 24.5 \\
\hline \multirow{2}{*}{$\begin{array}{l}\text { Other power gener- } \\
\text { ating machinery }\end{array}$} & 718 & & 1971 & 23.2 & 5.5 & 11.6 & 6.1 \\
\hline & & 1726 & 1980 & 29.1 & - & - & 17.5 \\
\hline $\begin{array}{l}\text { Electric power } \\
\text { machinery }\end{array}$ & 771 & 3432 & $1980^{\mathrm{a}}$ & 27.1 & 2.3 & 0.4 & 23.7 \\
\hline Switch gears & 772 & & 1971 & 22.1 & 4.6 & 8.1 & 9.1 \\
\hline Parts & & 12,589 & 1980 & 34.3 & 5.9 & 7.3 & 20.8 \\
\hline \multirow{2}{*}{$\begin{array}{l}\text { Electricity distribu- } \\
\text { tion equipment }\end{array}$} & 773 & & 1971 & 37.8 & 8.6 & 7.2 & 21.0 \\
\hline & & 5462 & 1980 & 51.7 & 8.9 & 8.4 & 34.4 \\
\hline \multirow{2}{*}{$\begin{array}{l}\text { Transistors, } \\
\text { valves, etc. }\end{array}$} & 776 & & 1971 & 10.6 & 0.5 & 4.9 & 5.2 \\
\hline & & 15,162 & 1980 & 24.8 & 0.3 & 2.6 & 21.9 \\
\hline \multirow[t]{2}{*}{ Electric machinery } & 778 & & 1971 & 25.6 & 4.3 & 8.3 & 12.8 \\
\hline & & 14,403 & 1979 & 26.2 & 5.2 & 6.0 & 15.0 \\
\hline
\end{tabular}

Source: United Nations Yearbook of International Trade Statistics (1979).

${ }^{a}$ Major fractions of the equipment are likely to be used by power industries, but some of it could also be used by other industries. On the other hand, the list given does not include all possible items required by power industries.

'There appear to have been reorganizations in the trade statistics in the year 1980, so that some of the commodity groups' coverages are different.

'This total may exceed the sum of the three regional totals because of the exclusion of small countries in Oceania and centrally planned Asia. Sometimes the percentage distribution for 1980 is not available and the 1979 distribution is reported. No data prior to 1976 are available for item 771 . 
for steam turbines, gas turbines, electricity distribution equipment, and other capital goods (J. Parikh, 10). Imports of only a few items add up to US\$15 billion.

A few developing countries also export some of these items, but at low levels, as discussed in the next section.

\subsection{Trends in the World Trade in Electric Power Equipment}

Let us look at the basic facts, recent trends, and current positions regarding trade in electric power equipment and its destinations during the period 1970-1983 by country groups. In fact, since the trade data are more reliable than the manufacturing data, many of the inferences about manufacturing of power equipment could also be drawn from trade data, albeit indirectly, as will be shown later. Discussions are split into three categories:

1. Some general global trends at three-digit levels $;^{3}$

2. structural changes in the trends ;

3. specific trends of exports and imports by countries or groups of countries.

2.2.1 GENERAL TRENDS ${ }^{4}$ The short summary in Table 3 illustrates general world trends. It can be seen that in current dollars, total world exports amounted in 1970,1980 , and 1983 to US\$13, 39, and 34 billion, respectively. However, developing countries's shares of world exports differ for different items; the share is nearly $45 \%$ for electricity-distributing machinery, whereas it is $26 \%$ for nonelectric power-generating machinery, i.e. high-technology items, such as boilers, turbines, etc. These differences result from the fact that some developed countries also import these hightechnology items.

\subsubsection{STRUCTURAL CHANGES Several structural changes are highlighted below.}

There was a substantial rise in world trade in power equipment of all types, from US\$13.2 billion to US\$39.3 billion during the period 1970 -

\footnotetext{
${ }^{3}$ These are broad categories classifying equipment into nonelectric power-generating machinery, electric power machincry, and switch gcar and clcctricity distribution machinery, classified by SITC codes nos. 711,722 , and 723 , respectively. This is not the only equipment required for electricity generation. Therefore, the final figure of total trade would be much larger. In the introduction, an average increase of $30 \%$ is assumed due to remaining equipment.

${ }^{4}$ This discussion includes only items under SITC nos. 711, 722, and 723, and excludes miscellaneous items which could add $30 \%$ to the costs.
} 
Table 3 Summary of world trade in the electric power equipment industry (in billions of US dollars, at constant 1975 prices)

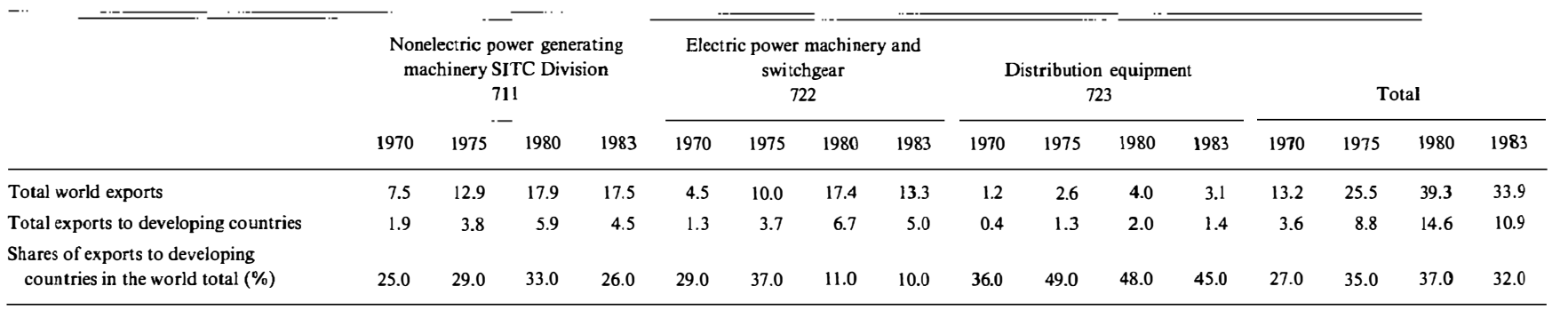

Source: UN statistics $(1975,1980)$ 
1980 , after which it dropped in 1983 to US $\$ 33.9$ billion. The drop is due to reduced electricity demand, which has become a worldwide phenomenon, especially noticeable in the developed countries. However, in the developed countries the drop is in part due to increased efficiency of electricity, while in the developing countries it is mainly due to the countries' inability to finance such imports.

The shares of developing countries in the world market rose from $27 \%$ to $37 \%$ between 1970 and 1980 , but declined to $32 \%$ in 1983 . The decline since 1980 is somewhat surprising because the fall in electricity demand has been much greater in the developed countries than in the developing countries. This can perhaps be explained partly by the increased ability to domestically manufacture the equipment and by the lack of financial means compounded by the reduced demand even in the Organization of Petroleum Exporting Countries (OPEC).

For all three items, the United States' share in world exports remained nearly the same with only minor fluctuations from 1970 to 1983 , while Japan's share steadily increased during this period. As a result, the shares of the exports of the other Organization for Economic Cooperation and Development (OECD) countries fell considerably. This is rather surprising considering that the value of the US dollar was high during 1983 compared to its value in 1980, and these countries would be expected to be more competitive than the United States.

The largest exporters of capital goods for energy are the European Community and the United States, but Japan is also claiming a share in recent times. Table 4 shows exports of the major items. The general breakdown of all items appears to be $50 \%, 17 \%$, and $13 \%$, respectively, for the three exporters. The information in this table should be interpreted with care, and the footnote on the difficulties with data needs to be kept in mind. The European Community also imports some items with the same general commodity number, and some of these exports could be to countries within the European Community. However, even when that is taken into consideration, its net exports are often the largest and, if not, at least significantly high.

There was a dramatic rise in the value of world exports around the years 1976-1978 (sometimes as much as two- or fourfold) for some high-technology items. For example, exports of switchgears jumped from $\$ 1045$ million in 1976 to $\$ 4803$ million in 1977 , and exports of pumps for gases increased from \$534 million to \$2294 million during 1977-1978. Since it is unlikely that so much additional capacity was created in less than two years, it is most plausible that a significant rise in prices took place. 
Table 4 Changes in exports of capital goods

\begin{tabular}{|c|c|c|c|c|c|c|c|c|}
\hline \multirow[b]{2}{*}{$\begin{array}{c}\text { Item } \\
\text { description }\end{array}$} & \multirow[b]{2}{*}{$\begin{array}{c}\text { SITC } \\
\text { no. }\end{array}$} & \multicolumn{2}{|c|}{ Exports in $10^{6} \mathrm{~S}$} & \multirow{2}{*}{$\begin{array}{c}\text { Annual } \\
\text { growth } \\
\text { rate (\%) } \\
1976-1980\end{array}$} & \multirow[b]{2}{*}{ Year } & \multicolumn{3}{|c|}{ Shares of exporters } \\
\hline & & 1976 & 1980 & & & EC & Japan & US \\
\hline $\begin{array}{c}\text { Steam boilers and } \\
\text { auxiliary plant }\end{array}$ & 711 & 989 & 1594 & 12.7 & $\begin{array}{l}1971 \\
1980\end{array}$ & $\begin{array}{l}56.3 \\
47.5\end{array}$ & $\begin{array}{l}10.7 \\
22.2\end{array}$ & $\begin{array}{l}19.3 \\
19.6\end{array}$ \\
\hline Steam turbines & 712 & 793 & 1439 & 16.1 & $\begin{array}{l}1971 \\
1980\end{array}$ & $\begin{array}{l}52.7 \\
49.5\end{array}$ & $\begin{array}{l}10.8 \\
14.2\end{array}$ & $\begin{array}{l}13.1 \\
19.2\end{array}$ \\
\hline $\begin{array}{l}\text { Other power-generat- } \\
\text { ing machinery }\end{array}$ & 718 & 550 & 1903 & 36.3 & $\begin{array}{l}1971 \\
1980\end{array}$ & $\begin{array}{l}48.4 \\
50.8\end{array}$ & $\begin{array}{r}20.5 \\
5.1\end{array}$ & $\begin{array}{l}17.4 \\
24.8\end{array}$ \\
\hline $\begin{array}{l}\text { Electric power } \\
\text { machinery NES }\end{array}$ & 771 & 512 & 3304 & 59.3 & 1980 & 50.2 & 17.7 & 9.6 \\
\hline $\begin{array}{l}\text { Switch gears } \\
\text { Parts NES }\end{array}$ & 772 & 5661 & 12,663 & 23.7 & $\begin{array}{l}1971 \\
1980\end{array}$ & $\begin{array}{l}59.7 \\
55.1\end{array}$ & $\begin{array}{r}7.1 \\
12.9\end{array}$ & $\begin{array}{l}17.2 \\
14.1\end{array}$ \\
\hline $\begin{array}{l}\text { Electricity distribu- } \\
\text { tion equipment }\end{array}$ & 773 & 2641 & 5279 & 18.9 & $\begin{array}{l}1971 \\
1980\end{array}$ & $\begin{array}{l}53.7 \\
48.2\end{array}$ & $\begin{array}{l}13.3 \\
17.7\end{array}$ & $\begin{array}{l}10.3 \\
10.1\end{array}$ \\
\hline $\begin{array}{l}\text { Transistors, } \\
\text { valves, etc }\end{array}$ & 776 & 5863 & 13,465 & 23.1 & $\begin{array}{l}1971 \\
1980\end{array}$ & $\begin{array}{l}46.5 \\
27.7\end{array}$ & $\begin{array}{r}7.6 \\
16.1\end{array}$ & $\begin{array}{l}33.7 \\
18.1\end{array}$ \\
\hline Electric machinery & 778 & 7133 & 14,190 & 18.8 & $\begin{array}{l}1971 \\
1980\end{array}$ & $\begin{array}{l}54.1 \\
51.0\end{array}$ & $\begin{array}{l}12.0 \\
16.0\end{array}$ & $\begin{array}{l}17.1 \\
16.4\end{array}$ \\
\hline
\end{tabular}

See footnotes for Table 2. The exports are not all to developing countries for which Table 2 for imports needs to be seen. Some of the items are used for general industrial purposes and not for power generation alone.

\subsection{Integrated Planning for Electric Power Equipment: National Objectives and Economic Planning}

Planning for electric power equipment must be integrated with national objectives, economic planning, and the development of other sectors of the economy, including the various subsectors.

In setting national objectives, the availability of natural resources (including land, mineral resources, water, and soil, geoclimatological features, and cultural and traditional factors need to be considered to maximize natural advantages and minimize vulnerabilities and risks. These national objectives and their rationales need to be considered in economic planning. For example, low-income countries, whose primary goals are to ensure basic necessities to people, may emphasize food production; therefore, substantial shares of energy and electricity would be required for food processing, households, irrigation, and the like. (Exceptions are India and China, whose large sizes necessitate significant industrial bases.) On the other hand, high-income developing countries that are also 
industrializing may need different types of industries and rather advanced service sectors, and their energy and electricity requirements would therefore be different. Thus, economic planning (J. Parikh, 11) would lay down the ground rules for the interrelationships in the development of agriculture, industry, energy, and other sectors, such as transport and housing. The present paper is concerned with the planning of industry and energy and the linkages among industry, energy, and electricity.

Figure 1 illustrates this hierarchy and the industry-energy-electricity nexus within the rest of the economy, which needs to be considered before assigning priorities to the manufacture of electric power equipment.

Long-term energy planning is a prerequisite to identif ying actual projects for energy development and to planning for the manufacture of power equipment. Energy planners should consider the future demand for energy for the rising population and income, the availability of mineral and renewable energy resources, the need for fuel substitution through electricity, if any, and in general the role of electricity in overall energy requirements. Moreover, electricity generation itself would require either mineral or renewable energy resources, which therefore play an important role in electricity planning.

Long-term industry planning also requires consideration of available skills, mineral resources, the supply of intermediate goods, technical inf ra-

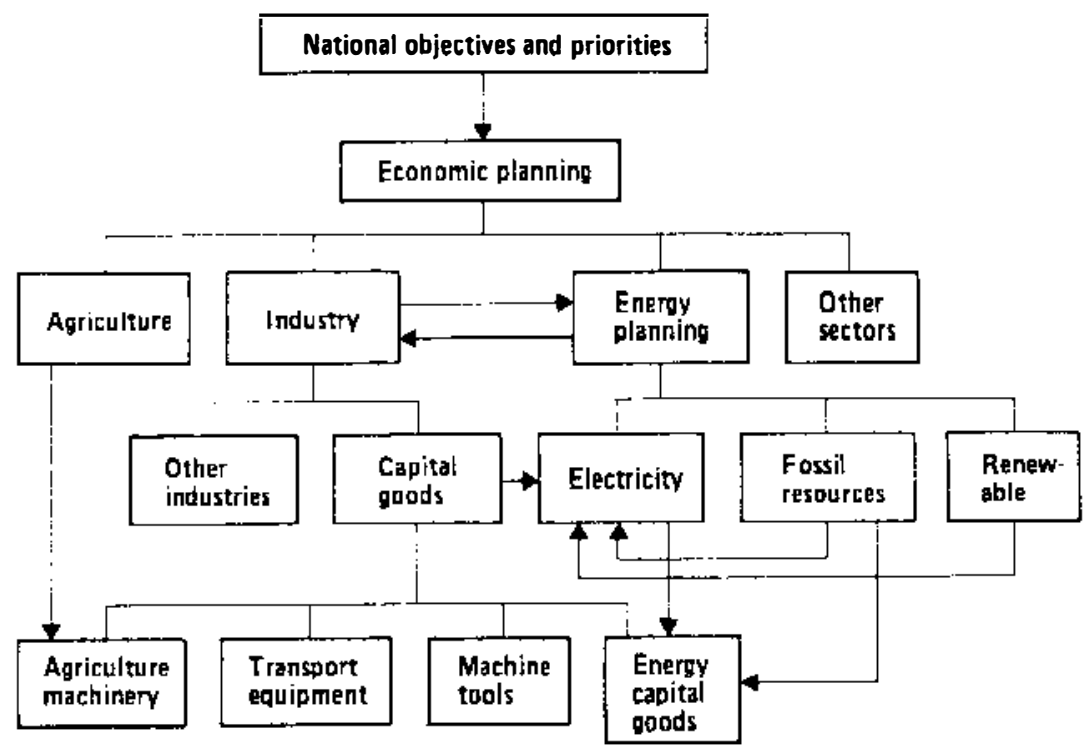

Figure 1 Interdependence of sectors indicating the need for integrated planning. 
structure, and available financial resources. In general, industries based on primary resources, such as textiles, paper, or cement, have received greater attention in the devcloping countries than capital goods industries, which require higher infrastructure, skills, and capital, and assured high demand. Even in the capital goods sector, there is a variety of alternatives and priorities that need to be assigned among, for example, agricultural machinery, machine tools, transport equipment, and energy-related capital goods.

Should the developing countries continue to import equipment, or should they try to manufacture some equipment? Which countries should or should not manufacture what equipment? We discuss these questions next, as well as alternative paths to self-reliance.

\section{REGROUPING OF COMMODITIES AND COUNTRY GROUPS}

When one considers an issue that covers a large number of commodities and more than 100 countries, a conceptual framework for aggregation and grouping is necessary. Otherwise, it may be difficult to formulate the problem and suggest policy prescriptions. This section develops principles for classifying technologies and countries.

\subsection{Classification of Equipment into Levels of Technologies}

As indicated in $(10,12)$, the list of equipment is so large that some principle of aggregation is required. This aggregation is more for convenience and clarity of issues than for making actual plans, and may vary with the specific issues being addressed. Here, several indicators, together or separately, must be checked before classifying equipment into high-, medium-, or low-technology items. These indicators a re discussed below :

1. Size and scale of the item: This factor is crucial for manufacturing certain items, such as $50 \mathrm{MW}$ or $500 \mathrm{MW}$ power plants or $33 \mathrm{kV}$ or $400 \mathrm{kV}$ transmission lines. The former may be easier to manufacture than the latter.

2. Demand for units of the item : If a large number of units are required every year, mainly due to domestic demand but also for possible export, development of that technology becomes economically attractive. Sometimes that demand permits a number of manufacturers to make the same product as in the case of insulated wires.

3. Precision and skills required for manufacturing: Some large and even some small items may require precision of high order and therefore 
specific skills and infrastructure that may not be available. Large generators and controlling and measuring equipment are examples.

Decisionmakers choosing between domestic manufacture and imports of an item need to balance these three indicators. Of course, other factors as well need to be balanced, such as the relative factor costs of inputs, international prices, the opportunity costs of proposed investments, and relative advantages, but these factors do not relate to classification of technologies. Skills, infrastructure, critical size, and demand levels are usually overriding factors that determine the prima facie feasibility of domestic manufacture in a reasonable time compared to factors such as labor intensities or current prices, which are subject to major revisions and which affect mainly the economic evaluation. It therefore seems reasonable to consider first the feasibility of manufacturing capital goods for energy development, and in particular the development of capital goods industries for the power sector. Based on these indicators the following classification principles have evolved.

The classification relates only to energy industries and does not refer to other industries. Moreover, it shows only broad patterns and would undoubtedly have exceptions in particular situations.

3.1.1 HIGH-TECHNOLOGY ITEMS Large-size equipment and/or equipment that requires high skills and precision in manufacturing generally fall into the category of high-technology items. Sometimes they are not required in large number and therefore there are only a few manufacturers, often only one in a country, if any (J. Surrey, 13). They include large items like turbines, generators, and boilers, as well as precision items such as controlling equipment, all of which require a high order of skills and precision to manufacture. They relate in particular to large-scale power generation and distribution, offshore oil exploration, deep coal mining, and the like. Occasionally, they are required for specific locations and difficult situations, such as certain seismic conditions.

3.1.2 MEDIUM-TECHNOLOGY ITEMS Transformers, compressors, liquid pumps, and similar items, are considered medium technology. They are required in large number and can often be manufactured by several manufacturers in a country. They require precision and skills, but not of an especially high order. Some are required also by industries other than the energy industries, leading to higher demand.

3.1.3 LOW-TECHNOLOGY ITEMS Items such as insulating cables, fuses, and valves, required in large number and manufacturable in the unorganized sector, are considered low-technology. They can be made by 
semiskilled persons and require low precision (but this technology level may still be high for the rural areas of developing countries).

It should be stressed again that some items such as insulating cables or transformers may require high or medium technology if they are to be used in high-voltage transmission. Thus, without labeling each item in detail, the above classification is not precise. However, for discussion purposes it suffices.

\subsection{Groups in the Countries of the South and China}

It is conventional to classify developing countries according to geographical locations (Africa, the Mid-East, and so on) by income levels (high-, medium-, and low-income countries of the World Bank), or as oil importers, oil exporters, OPEC, or non-OPEC members and so on. None of these classifications are appropriate for explaining manufacturing capabilities in general or energy capital goods in particular. We require instead a classification that considers the critical size of the economy required for developing domestic manufacturing capabilities. The countries with significant domestic manufacturing bases have large demand due to either large populations or high incomes. Thus, classification based on per capita indicators would be inadequate.

The following classification of countries seems appropriate for discussing structural changes in North-South trade. The basis of such classification for each group of the South is discussed below. A full list of all countries is given at the end of the paper in Appendix 1, and their collective attributes are given in Table 5 .

SOUTH 1 (OR BIG COUNTRIES) This group consists of countries presently engaged in manufacturing equipment requiring skills and equipment of somewhat large-scale nature. Thus, it includes countries with large industrial bases, such as South Korea, and also large countries, such as China (which is also included here because its characteristics are similar to those of the countries of South 1, although it is in the northern hemisphere), India, Mexico, Brazil, and Argentina. Annual energy consumption in these countries is at least 30 million tons of oil equivalent ( $30 \mathrm{mtoe}$ ), and annual increments of power capacity are of the order of $1000 \mathrm{MW}$. Part of their demand, due either to large size (India) or to high income (Venezuela) or both (Mexico), is for large-scale equipment, such as boilers and turbines for 200-800 MW power plants, and $400 \mathrm{kV}$ transmission lines. They can import directly what the North has to offer. On the other hand, some have already achieved some ability to manufacture medium-scale items such as switch gears and transmission towers, and much of the equipment neces- 
sary for 100-300 MW power plants, including high-technology items. In fact, some of these countries already export to other developing countries, e.g. equipment for $50-100 \mathrm{MW}$ power plants, or could be expected to compete in the future in exporting such equipment. But such exports are at a very small scale because some countries, at present, can barely keep up with their own demand targets. Note that India and China, which are low-income countries, are included along with Brazil, Mexico, and other high-income countries simply because they have large demand bases (more than $3000 \mathrm{MW}$ addition in a year), making it possible to go into indigenous manufacturing. On the other hand, Pakistan and Malaysia, which also have skilled manpower but whose annual demand increment is low (800 MW split into several units) may not find it worthwhile to invest in indigenous manufacturing capacity for all types of power equipment.

Nature of trade with South 1 Thus, exports from North to South 1 would be restricted mainly to high-technology items, but nevertheless attractive to exporters because of the large demand, and because the scale of items is compatible with the scale in the North (for example, power plants larger than $500 \mathrm{MW}$, typically used in the developed countries). The names of the countries are given in Appendix 1.

Table 5 Population, energy consumption, its growth rate, and power capacity in reorganized developing regions

\begin{tabular}{|c|c|c|c|c|c|c|}
\hline \multirow{2}{*}{$\begin{array}{c}\text { Country } \\
\text { groups }\end{array}$} & \multirow{2}{*}{$\begin{array}{l}\text { Number of } \\
\text { countries }^{\mathrm{a}}\end{array}$} & \multicolumn{2}{|c|}{$\begin{array}{l}\text { Commercial } \\
\text { energy } \\
\text { consumption } \\
\left(10^{6} \text { toe }\right)\end{array}$} & \multirow{2}{*}{$\begin{array}{c}\text { Growth } \\
\text { rate } \\
(\%) \\
1970-1981\end{array}$} & \multirow{2}{*}{$\begin{array}{c}\text { Electric } \\
\text { capacity } \\
(\mathrm{GW})^{\mathrm{a}} \\
1981\end{array}$} & \multirow{2}{*}{$\begin{array}{c}\text { Population } \\
10^{6} \\
\text { mid-1981 }\end{array}$} \\
\hline & & 1970 & 1981 & & & \\
\hline South 1 & 7 & $\begin{array}{c}380 \\
(67 \%)\end{array}$ & $\begin{array}{c}739 \\
(67 \%)\end{array}$ & 6.2 & $\begin{array}{c}197 \\
(64 \%)\end{array}$ & $\begin{array}{c}1955.7 \\
(58.4 \%)\end{array}$ \\
\hline South 2 & 29 & $\begin{array}{c}134 \\
(24 \%)\end{array}$ & $\begin{array}{c}276 \\
(25 \%)\end{array}$ & 6.7 & $\begin{array}{c}76 \\
(29 \%)\end{array}$ & $\begin{array}{c}914.9 \\
(27.3 \%)\end{array}$ \\
\hline South 3 & 92 & $\begin{array}{c}50 \\
(9 \%)\end{array}$ & $\begin{array}{c}134 \\
(8 \%)\end{array}$ & 6.0 & $\begin{array}{c}36 \\
(11 \%)\end{array}$ & $\begin{array}{c}477.6 \\
(14.3 \%)\end{array}$ \\
\hline Total & 128 & 564 & 1109 & 6.3 & 309 & 3348.2 \\
\hline
\end{tabular}

\footnotetext{
a Based on energy data given by the United Nations Yearbook of World Energy Statistics (1980). Population statistics from the World Bank World Development Report (1983), including only countries with population larger than one million. South 1 includes countries with energy consumption of $30 \mathrm{mtoe}$ per year and above and power capacity of about 10,000 MW and above. It includes Argentina, Brazil, China, India, Mexico, South Korea, and Venezuela. South 2 excludes those countries with population less than 5 million and those already included in South 1. South 3 includes the remaining small countries. For the names of the countries included in each category, see Appendix 1. Numbers in brackets are the shares of each country group in the total of all developing countries given at the bottom of the table.
} 
SOUTH 2 (OR MEDIUM COUNTRIES) Having already explained the logic behind the South 1 countries, it is sufficient to say that South 2 consists of countries that are or could be engaged in using and manufacturing medium- and low-technology items, including medium-sized countries like Colombia, Peru, Pakistan, Indonesia, and Malaysia. Their populations, barring a few exceptions, range from 10 million to 120 million. During 19701979 , most of these countries added power capacity of $2500 \mathrm{MW}$ and more. They do not manufacture high-technology items. They generally import some of their capital goods from the North, and their requirements are small individually but reasonably large collectively. They can import some of the capital goods from South 1 countries also, if South 1 has excess capacity beyond its own requirements.

Nature of trade with South 2 South 2 countries import items of high and medium technology but require medium- or small-scale items (50 MW to $200 \mathrm{MW}$ plants), which are not normally produced in quantity in the North. Thus, satisf ying this demand would entail a special order requiring considerable reorientation of production facilities in the North.

SOUTH 3 This group consists of numerous small countries that may not find it worthwhile to manufacture high-technology items and, in some cases, even medium- and low-technology items. Some countries of this group, such as the least developed countries, may find it difficult even to maintain their power systems, lacking spare parts and skilled personnel. They may require assistance from the North and South not only financially but also in the form of technical assistance for power system planning. Their annual increase in demand usually ranges from $1 \mathrm{MW}$ to $50 \mathrm{MW}$ at most, and sometimes is even in the kilowatt range, which is much less than the standard unit size of $500 \mathrm{MW}$ in which the countries of the North specialize. Most of the countries of this category added less than $250 \mathrm{MW}$ during 1970-1979. It is possible that they do not make "interesting clients" for the North strictly for trade reasons. However, they suffer the most from fluctuations and uncertainties in energy supply, and efforts need to be made to help them.

Note that the classification of countries as members of South 1, South 2 , or South 3 had to be based on absolute rather than per capita levels of power capacity or energy consumption to address the issues that are raised in this paper. In addition, there will always be borderline countries that could be in a neighboring group depending on the cut-off points chosen. Exceptions had to be made in the case of Egypt, which is put into South 2 rather than in South 3 in spite of nearly zero increment of capacity during 1970-1979, and several other countries. Inclusion of Bangladesh in South 2 rather than South 3 in spite of its being the least developed country 
is not surprising considering the large population, the availability of skilled persons, and the small but not negligible manufacturing base. Even the OPEC countries had to be split into different groups depending on the size of demand and available industrial infrastructure.

\subsection{Insights due to Reclassification of Country Groups and Equipment}

How does the reclassified picture differ from that presented in Section 2 in world regional terms? What additional insights are obtained from it? This way of organizing countries leads to clearer patterns and explains variations among them in terms of three indicators :

1. Energy consumption and capacity for electricity production,

2. imports of capital goods,

3. manufacture of capital goods.

South 1, South 2, and South 3 represent 7, 29, and 92 countries and have $59 \%, 27 \%$, and $14 \%$ of the population of the developing countries, respectively.

3.3.1 ENERGY CONSUMPTION AND CAPACITY FOR ELECTRICITY GENERATION Table 5 shows that energy consumption of South 1, South 2, and South 3 in 1981 was 739, 237, and 134 mtoe, respectively, of primary energy. During 1970-1981, their growth rates were $6.2 \%, 6.7 \%$, and $6.0 \%$, respectively. The shares of each in the total energy consumption by developing regions are $66 \%, 24 \%$, and $9 \%$, respectively. With regard to the capacity for electricity generation, the shares of the three regions in the total capacity in the developing world in 1981 were $64 \%, 29 \%$, and $11 \%$, respectively.

3.3.2 IMPORTS OF CAPITAL GOODS Imports of capital goods also have different patterns for South 1, South 2, and South 3. Since the countries of South 1 have their own industrial bases, they do not import many low- and medium-technology items. (Power transmission and distribution equipment account for only $8 \%$ of the $\$ 3814$ million spent on the four items.) It appears that only Mexico imports them. Thus, among their imports power-generating machinery has a much larger share. On the other hand, the countries of South 2 make an interesting case for studying the rise in imports of oil vs the imports for the power industry, and the price escalation in each. For the sake of such a comparison over a 12-year period, data for Egypt and Chile - for which disaggregated data up to 1967 are available - are tabulated. It should be emphasized that only four major commodities for power are considered, and that they represent only a part of the total imports of capital goods for the power industry.

Egypt's example may be relevant to many countries that are turning 
into crude oil producers faster than they can manufacture capital goods for energy industries. For such countries, the ratio of the value of imports of capital goods to the value of exports of petroleum may increase because of changes in prices of capital goods. Such countries include Mexico, Malaysia, Sudan, and Peru.

\section{EVOLUTION FROM IMPORTS TO INDIGENIZATION}

\subsection{Is Indigenization Necessary? To What Extent? For Whom?}

Several arguments could be made against increased efforts by the developing countries for indigenization in the production of power equipment. Some of them may be valid in some situations but not in others. The arguments are discussed below to illustrate why and when they are valid and what exceptions should be made.

It may be difficult to justify efforts to build up a technical capacity that is not required or is not required in sufficient magnitude. This is the situation for countries in South 3 that build less than $300 \mathrm{MW}$ in 5 years and for some countries in South 2. However, even in this case, indigenization of production of auxiliary equipment for transmission and equipment that could be used in other sectors, such as motors or transformers, could be appropriate.

Every country has different priorities for different sectors, and some countries may find indigenization of production of transport equipment, agricultural machinery, machine tools, or consumer goods more worthwhile than manufacturing power equipment. Here again, the question of overall national objectives, and hence priorities for industrialization, comes into play because it may not be possible to pursue several goals at the same time, given limited financial and manpower resources. Therefore, as discussed in Section 2, whether the power sector has priority over other sectors needs to be determined in overall economic planning.

At present, the most important factor militating against the domestic manuf acture of power equipment in the developing countries is the surplus capacity that exists at the global level due to falling or stagnant demand for capital goods for electricity in the western world. One would think that this might be an opportunity for North-South trade. Unfortunately, it has not led to a spurt of buying from the developing countries. There are several reasons :

1. Falling demand in the West has tended to increase overheads and hence prices of imports by the developing countries, as indicated in the changes in World Bank assumptions between 1980 (1) and 1982 (8). Of course, 
the costs of civil works and the like in the developing countries have gone up too, but the price increase in high-technology items has been more significant. The high exchange rate for the dollar since 1982 has worsened the problem. Even if some prices did not go up in US dollars, there was nearly a $60 \%$ rise in the value of the dollar itself as measured against the national currencies of most developing countries during this period.

2. The shortage of financing has also led to great restraint by the developing countries as well as the financing agencies.

3. The countries of South 1, which could provide large markets for the North, have only recently acquired self-sufficiency in domestic manufacturing and are at a cross-roads of decision on whether to support domestic firms by giving them the opportunity or to seek better equipment a vailable from foreign firms, which sometimes also brings external financing in the bargain.

Thus, there is a conflict between the short-term goal of obtaining power plants rapidly and the long-term objective of increasing self-reliance. A delicate balance between the two can be achieved with farsighted policies. The slow process of training, which requires bearing the costs of "learning by doing" and putting faith in national talents and capabilities, constitutes the kind of measure necessary to build up technological self-reliance (14, 15).

Taking many factors into account, including world surplus capacity, sources of financing and technological constraints, different developing countries may wish to pursue self-reliance to different extents, while cautiously taking into consideration the surplus production capacity in the world and the relative priorities among various competing capital goods sectors. However, in all cases there is a need to develop the indigenous capacity to carry out planning and feasibility studies as well as to obtain the basic understanding of the technology necessary for identifying the individual components of turnkey projects, which are delivered as single packages. This identification of components is referred to as "unpackaging." Even in the case of a turnkey import, they should ensure better delivery and stipulate contractual terms that avoid misunderstandings leading to delays, increased costs, or inadequate returns for their money.

\subsection{Gradual Steps to Indigenization}

It has been shown that there is a gradual transition in what a country can manuf acture, starting from simple low-technology items like cables, valves, and transformers, then progressing to high-technology items like generators and turbines. A country that relies completely on imports of turn- 
key projects could gradually strengthen its capacity to indigenize depending on the demand parameters. Such a transition may or may not be completed, depending on the policies pursued. In any case, while a few steps could be bypassed, no country is likely to jump from total reliance on imports to complete indigenization without going through intermediate steps, described below, to develop the necessary skills and infrastructure.

The relative advantages, constraints, and prerequisites of each of these steps or modes of action are discussed below. It should be borne in mind that the ordering of these steps may vary. Better contractual terms with exporters at each step would make learning easier for importers and ensure proper delivery.

Let us recall the earlier distinction between power systems and power projects. The former includes the entire network with transmission and distribution system, while the latter refers to a single project for a new power facility. Similarly, it is appropriate to mention the distinction between unpackaging projects and unpackaging technology. The former involves planning and design, feasibility studies, choosing parameters and specifications of different components, assembling and installing hardware, on-site construction, etc. Some of this can be done gradually by a team of skilled and trained persons without entering the manufacturing phase. Unpackaging technology, on the other hand, requires an understanding of the designs and manufacturing processes for individual components, as well as their actual manuf acture, including testing and quality control. The first three steps mentioned below deal with unpackaging projects, and the next four with manuf acturing the equipment for power generation as well as transmission and distribution.

\subsubsection{TURNKEY IMPORT FROM A SINGLE SOURCE Many developing coun-} tries of South 2 and South 3 and even South 1, in the case of urgent projects, follow this course. The project is often completed with speed and reliability, and a single source takes responsibility for its execution. The exporter naturally charges a high premium for risk factors, to ensure recovery of costs that may arise owing to the failure of components or subcontractors. Therefore, the project involves significant foreign exchange. The responsible firm subcontracts with other firms of its own choice and takes the responsibility of matching all the specifications of different components from different sources a nd exercising quality control. Apart from paying high costs, a country may not always get what is in its best interest, if all the responsibility is given to others.

\subsubsection{ASSEMBLING FROM DIFFERENT SOURCES OR FROM IMPORTED PARTS} This mode requires a competent team of skilled persons who know what is involved in ordering a plant and are in a position to match the different 
components, and therefore to obtain better bargains. However, the responsibility for quality control, and for minimizing the risk of failures, will lie with the team that orders the equipment. As components from domestic firms are substituted for imported ones, domestic firms could to a gradually increasing degree be encouraged to manuf acture parts.

4.2.3 FOREIGN SUBSIDIARIES As the domestic level of skills and the strength of the infrastructure increases, foreign firms may become interested in setting up subsidiaries by bringing capital and technology into the country. They do not, in general, part with proprietary technology, but there are many nonproprietary technical activities in which domestic talents can be used and developed. This provides employment and a work environment from which skilled and semiskilled persons can learn. Moreover, the equipment made will, in all likelihood, meet domestic performance requirements because the firms will be primarily interested in capturing home markets. However, the success of this mode of action depends on the host country's economic policies, which may offer incentives to foreign firms to encourage such ventures, including the right of the subsidiary to repatriate its profits.

4.2.4 DOMESTIC MANUFACTURING UNDER LICENSE As the technological infrastructure becomes still stronger, and the domestic market expands, domestic firms may become interested in manufacturing equipment themselves, either under license, or by copying items whose patents have expired or items not covered by patents. Some low-technology items, such as cables, valves, and fuses, could be produced domestically in this mode when direct imports of such small items could lead to delays and cumbersome processes. However, for more complex items, this mode can be difficult. In general, it involves modifications in designs to suit local conditions, such as high humidity, high temperatures, or high winds, as well as designs that can withstand fluctuating voltage and current.

4.2.5 JOINT COLLABORATION AND VENTURES At still higher technological levels in the host country, foreign firms may be interested in taking domestic firms as partners, sharing both equity interest and design and management responsibilities. Here again, suitable government policies may be necessary. (Depending on contractual terms concerning technology transfer, this mode may or may not be superior to the previous one.)

4.2.6 COMPLETE INDIGENIZATION This course involves total disengagement from foreign firms. It is, of course, not difficult in the case of low- and medium-technology items, but with more complex items it requires experience in design and innovation. Complete know-how may require local research and development efforts as well. This is the final 
step of the process of industrialization, which is complete only when the developing country begins to become economically competitive with developed countries in manufacturing a given item of equipment with minimal difference in quality.

Developing countries' choices from among these alternatives depend on their priorities for equipment; demand levels; the level of technology required for manufacturing the item (and its availability in the country); future expectations of cost relative to the cost of imported equipment; and so on. However, it should be stressed again that the hierarchy of modes given above might differ depending on the terms negotiated. Thus, efforts to obtain the best results for each mode would lead to productive use of skills and resources of the developing countries.

\subsection{Role of Government Policies: Some Examples for Different Modes}

In determining the policies for manufacturing or import of capital goods, the governments of the developing countries often have a stronger role than those of the developed market economies. Examples of the actions of the governments of specific countries from South 1 are described below to help in understanding the implications of various policies, to provide the insights needed to change policies in the future, and to provide guidance to other countries, to whom they may be indirectly relevant. Their modes of industrialization in energy capital goods, and their consequences are illustrated below; see (16-20).

Brazil, commited to a market economy, allows foreign subsidiaries to enter and compete with domestic firms (16). It does impose restrictions concerning financial management, i.e. repatriation of profits, import and export restrictions, taxes, etc, but it allows such companies to operate freely with regard to technology, patents, and innovation. The subsidiaries normally employ Brazilians, but responsibility for the critical policy decisions lies with the parent firms abroad. As a result, Brazil has access to the modern technologies and Brazilians obtain a certain type of training, derived from the work environment and the management practices and disciplines of the foreign firms. On the other hand, the foreign firms have little association with domestic firms, and since technology and patents remain with the parent firms, little experience is obtained in design and innovation. The existence of such subsidiaries forces domestic forms to be competitive because they compete for the same contracts through tenders, but since the domestic firms cannot afford research and development, they may be at a disadvantage. Nevertheless, over the years, Brazil has developed manufacturing capabilities of a high order and is reasonably diversified. Since Brazil is mainly interested in hydropower projects, con- 
centrated efforts are made in hydroelectric equipment. Brazil has the distinction of having built the world's largest dam at Itaipu, with a generating capacity of more than $12,000 \mathrm{MW}$. It has also taken strides in developing advanced technology for high-voltage transmission to carry electricity more than $1000 \mathrm{~km}$.

China has repeated older Soviet designs, possibly with some modifications, and has built up the largest generating capacity ( $71 \mathrm{GW}$ in 1981) of any developing country; large-scale hydropower accounts for $37 \%$, thermal generation for 59\%, and small-scale hydropower for the rest (17). China is thus diversified, like India. It has the indigenous capacity to build $300 \mathrm{MW}$ hydroelectric plants and thermal plants with a unit size of more than $1000 \mathrm{MW}$. It has more than 30 coal-fired mine-mouth power stations with capacities in excess of $250 \mathrm{MW}$. It completed a $534-\mathrm{km}$-long $330 \mathrm{kV}$ line in 1975 and a $595-\mathrm{km}$-long $500 \mathrm{kV}$ line in 1981.

Several of China's achievements represent the highest technological level that any developing country has achieved. However, China does not have the ability to build nuclear power plants. Chinese thermal power plants are rather inefficient, consuming nearly 0.7 tons of coal per $1000 \mathrm{kWh}$, compared to the average value of around 0.35 tons per $1000 \mathrm{kWh}$ in the developed countries.

India has built a capacity to indigenize a whole range of power system components; many low- and medium-technology items are manufactured in the private sector and the government's role is in supporting the public sector for high-technology items and turnkey projects. India is one of the few developing countries with experience in developing indigenous designs. Moreover, a large domestic market permits the public sector to use the same design a number of times before moving to the next larger scale, from $110 \mathrm{MW}$ to $210 \mathrm{MW}$ and then to $500 \mathrm{MW}$. India has gradually increased its capabilities from level to level, while attempting to expand exports of lower-level items to other developing countries and continuing to manufacture them for domestic use. The licensing and joint venture route has its costs, too, when repetition of antiquated designs leads to inefficient power plants. This drawback can be corrected by ensuring that changes in the designs of parent firms are incorporated in Indian designs. Unlike Brazil and the Republic of Korea, India needs both thermal and hydropower capacity, and therefore must make greater efforts. It is also the developing country most advanced in nuclear technology $(11,18,20)$.

The Republic of Korea has chosen licensing and joint ventures rather than allowing foreign subsidiaries (19). The government provides subsidies, but they are time-bound and could be phased out gradually. The government takes an active role in testing and quality control by obtaining feedbacks from the consumers and by introducing penalty clauses. However, excess capacity has been built up, so that domestic firms compete 
in a rather limited domestic market. Moreover, since much of the increasing domestic demand for power is expected to be met with nuclear plants, the capacity for building coal-fired thermal power plants would be primarily for export. Unfortunately, this is happening at a time when there is surplus capacity even in the developed countries, resulting in strong global competition for export markets, which would again call for government intervention if Korea is to meet this competition.

Mexico has reservations about foreign subsidiaries operating in the power field, because domestic firms and institutions do not benefit from them. Mexico prefers joint ventures, most of which are with US firms (14).

The concept of building power systems as opposed to manufacturing components is relevant here. Experience in manufacturing lies more with the larger countries like Brazil, India, and China rather than with Korea, Singapore, and other small countries, partly because of the size of the local markets and the consequent opportunities for descending the learning curve by repeated production of the same designs.

\section{ADDITIONAL FACTORS IN MANUFACTURING CAPITAL GOODS FOR ENERGY DEVELOPMENT}

The development of energy capital goods industries needs to be considered in a broad framework, including such other factors as requirements for engineering services and the availability of raw materials. Moreover, as unconventional energy resources, such as windmills, solar equipment, and bio-gas generators are developed, a new approach will be required for manufacturing capital goods, and for energy development in general. These considerations are discussed in this section, as summarized from (10).

In addition, issues related to the requirements of specific country groups need to be addressed, such as the need of OPEC countries to develop oil and gas exploration, production, refining, and transport. However, due to the unique nature of each group, it might be best to examine each group in a separate study.

\subsection{Engineering Services for Energy Development}

Once the energy capital goods are manufactured or imported, the energy facilities need to be constructed, for which engineering services are required. Engineering services of varied nature, requiring skills that are of ten unavailable in developing countries, are needed at three stages:

1. Prior to commissioning a project. At this stage, the required services include geological and seismic surveys; every type of facility-hydropower, coal, oil, or gas-will require a different type of survey. Fossil 
fuel exploration often requires special skills, and contracts for these services are sometimes given to foreign consultant firms even by countries of South 1 ; in some cases, equipment required is not purchased but obtained on loan. Thus, in case of exploration, reliable services for locating and siting are at least as important as the equipment. While local services could be helpful, their contribution is small in this case, especially in the countries of South 2 , where foreign help is often called for.

2. During construction. At this stage, local labor could provide more than half the services required, including construction of buildings and dams, making roads, laying railway lines to move coal, or digging to lay pipelines. In addition to unskilled labor, construction requires skilled services and supervision. The countries of South 1 are able to obtain most of these skilled services domestically, although help may be required for complex, large-scale projects, such as nuclear power plants. The countries of South 2 often need to work together with countries from which technologies are imported. The countries of South 3 are totally dependent, requiring turnkey projects.

3. Maintainance of facilities. Maintaining energy facilities requires skilled services as well as some routine work. Moreover, spare parts can require as much as $10 \%$ to $25 \%$ of the total expenses for capital goods for energy industries. Except for some occasional help from abroad for special problems, countries of South 1 and South 2 are able to find the manpower required for maintaining energy facilities domestically. This is not the case for many countries of South 3.

\subsection{Backward and Forward Linkages}

These linkages in the manufacture of energy capital goods are illustrated in Figure 2. Since the forward linkages with the utilizing sectors, which determine the need for electricity and thus for power equipment, have been discussed in Section 2, the discussion here concentrates on the backward linkages or prerequisites. The first prerequisite is, of course, the availability of energy resources for generating electricity, which may be either mineral (fossil or nuclear) or renewable (hydropower, wind, etc). The next concerns are the availability of components, and then the availability of the raw materials for power equipment. This analysis will help in analyzing the import vs manufacturing issues with respect to power industries. The major raw materials required for manufacturing are iron and steel, cement (and concrete), copper, and aluminum. Of course, steel could be of various types: carbon steel, stainless steel, low steel alloy, etc, each of which requires different levels of technological development.

Table 6 gives data reported by Bechtel (21) for the materials required in constructing 500-MW power facilities of various types, mainly in the 


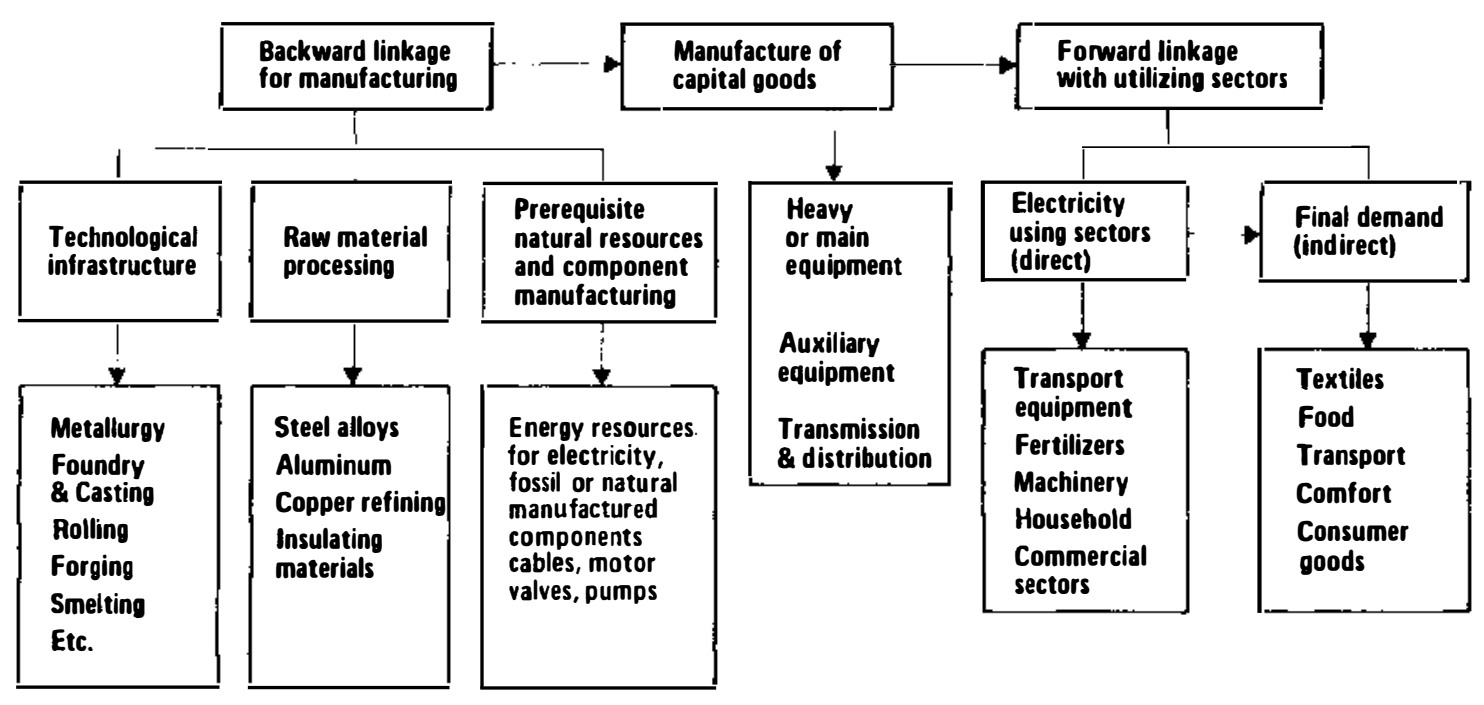

Figure 2 Backward and forward linkages essential for manufacturing power equipment. 
United States. In the table, requirements are scaled for 100-MW power plants without taking account of the economies of scale that may accrue to larger plants. Therefore, the amounts of raw materials required for an actual 100-MW plant may be higher than indicated in Table 6 .

It can be seen that dam and hydropower plants require much more cement, concrete, steel, copper, and aluminum than other power plants do. Thus, tapping renewable energy resources implies using nonrenewable metal and mineral resources. Surprisingly, nuclear power requires amounts of cement and steel comparable to those of hydropower. The requirements of materials for oil- and gas-fired power plants are less than those of coalfired plants. Geothermal power, on the other hand, requires more steel but not much cement. The source that requires the least materials is the latest gas-turbine technology.

In general, production by developing countries of these primary resources requiring low-level processing, such as cement or pig iron, as a fraction of world production is approximately proportional to their shares of world energy consumption. However, this is not the case for materials requiring high levels of processing, such as steel and aluminum, for which the shares of the developing regions in the world total are rather small. Figure 2 shows that while the number of developing countries having primary resources, such as iron ore, bauxite, or copper, is high, the number of those having the technology to process them is small. Many of them simply export the primary ore, and do not have the expertise in metallurgy required for smelting, casting, rolling, forging, etc. While auxiliary equipment of low and medium technology can still be made without the processing technology, the main equipment, i.e. boilers, turbines, etc, would require such a technological infrastructure.

\subsection{Energy Capital Goods for New and Renewable Sources of Energy}

Since, at present, the contribution of these sources of energy is negligible, there are no data available for manufacturing or trade in capital goods for them. However, it is essential to understand the implications of a policy to pursue development of these sources.

Much of the equipment necessary consists of low- or mediumtechnology items.

1. Bio-gas digesters, if bio-gas is used as fuel, could almost be made in rural areas, but pipes for transporting gas, good quality burners, and gas holders may have to be obtained from manufacturers in towns or urban areas. If bio-gas is used in engines, for mechanical purposes, it requires additional hardware, which is not simple. 
Table 6 Material requirements for $100 \mathrm{MW}$ power plants, in thousands of tons

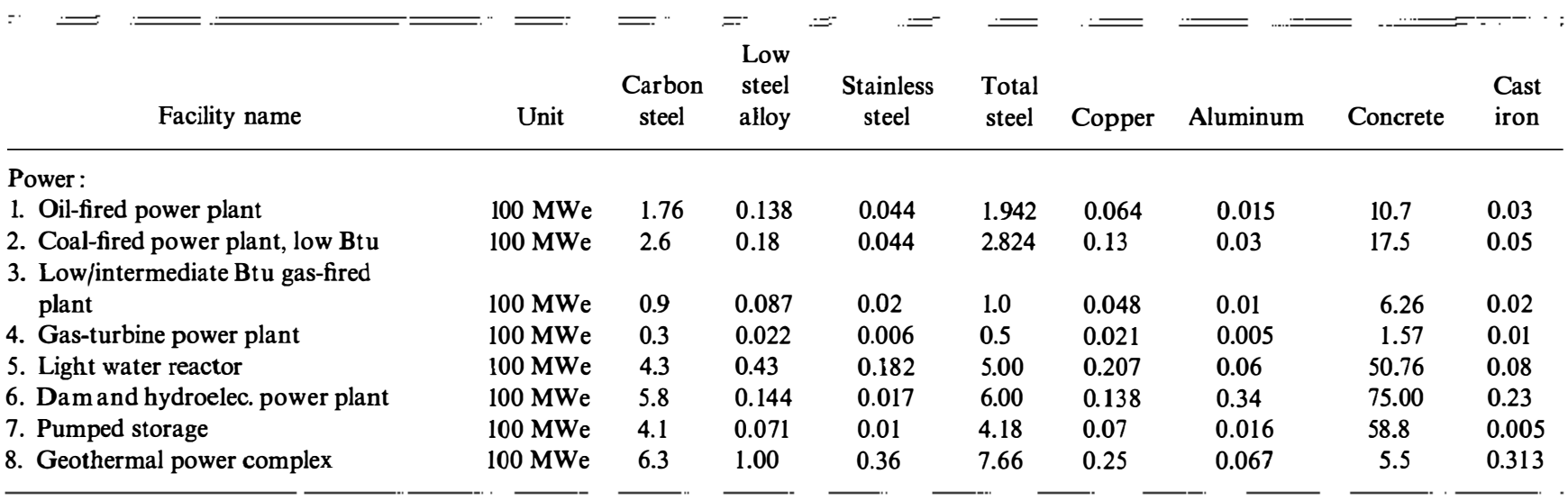

Note: The compiling and scaling of data were done by the author from the same basic source (Bechtel, 1). Since the scale of the facilities in the United States is larger, the scaling down to small facilities of $100 \mathrm{MWe}$, etc, may indicate smaller requirements than actually necessary. 
2. Windmills, if used for mechanical purposes, require low-technology items. Blades could be made of cloth, wood, or iron and steel. However, if used for electricity generation, they would require generators, which are medium- or high-technology items.

3. Solar energy, if tapped with collectors or concentrators for water heating or cooking or drying, does not require high-technology items. However, solar photovoltaic units and solar power plants for electricity generation---even if based on collectors-require high-technology items.

4. Items required for small-scale hydropower plants do not include hightechnology items.

Two conditions must be met for successful implementation of new or renewable energy sources.

1. Most applications require accurate siting and coordination. For example, the height and location of a windmill are so crucial that placement 50 meters away from the optimal site could mean reduced performance. The orientation and location of solar equipment and the height and site of small hydropower plants are similarly crucial. One may argue that this is also the case for large hydropower plants, but in that case it need be done only once to get large amounts of power. In the case of new and renewable sources, these investigations must be done many times over for an equivalent amount of energy. Thus, it would require the spread of different skills from those used in the present approach of large-scale, centralized energy production, in which teams of persons with high, medium, and low skills operate together.

2. If a large contribution from new and renewable sources is to be expected, then economies of scale must be replaced by "economies of number." For example, hundreds of windmills would be required to replace a conventional $200-\mathrm{MW}$ power plant. This development is certainly possible, as demonstrated by the computer industries, in which the march towards bigger and bigger computers stopped and turned toward small computers in large numbers, spreading the computing power to many persons. But new organizations and ways of working are not yet developed.

\section{HIGHLIGHTS AND IMPLICATIONS}

This article focuses on recent structural changes in the energy capital goods industries and the need for reorientation. The major structural changes of the 1970 s are: 
1. Energy demand and therefore demand for energy capital goods have declined sharply in the North, and demand for both in the South has declined moderately.

2. The composition of energy demand has changed, requiring less imported oil but more investment in oil and gas exploration, hydroelectricity, and other energy sources.

3. Volumes of trade have increased dramatically in the last four years, signif ying a major price increase, generally two- to fourfold, especially in high-technology items.

4. Shares of the developing countries in world imports have significantly increased.

In the following, important points are summarized as quantitatively as possible.

1. Imports of capital goods for energy industries vs oil imports. In 1980, developing countries spent nearly US\$25 billion to import capital goods for the energy sector, as against US\$34 billion to import crude oil. (In addition, nearly US\$10 billion were spent for petroleum products some of which are imported from the developed countries.) Some developing countries spend as much for energy equipment as for oil imports. Thus, imports of capital goods for energy development and imports of oil compete for scarce foreign exchange for the energy sector, but the former, which is essential to build up the nations, has received less attention from the media and policy analysts. In fact, in the 1980s the import bill for energy capital goods is expected to exceed the import bill for oil.

2. Predominance of electricity in the total energy sector. The energy sector often claims the largest share of public investment, even more than agriculture, industries, or transport. The electric power industries claim perhaps $60 \%$ to $90 \%$ for energy sector investment, especially in nonOPEC countries. The importance of power in overall investment is mainly due to its capital intensiveness and to expansions of networks in rural areas. Although import bills for oil can be large, they are annual expenditures and net investments. All countries produce electricity, but not all have fossil fuels of their own. The power sector in the developing countries claims about $5 \%$ to $10 \%$ of total capital formation in the economy, $17 \%$ to $20 \%$ of planned investment, and $65 \%$ to $90 \%$ of development aid and lending for the energy sector.

3. Large countries with critical size for manufacturing. Seven developing countries, which together represent $58 \%$ of the population, $67 \%$ of the energy consumption, and $64 \%$ of the electricity capacity of the developing countries, have the critical size and perhaps also the skills 
(but not the best organizations) to manufacture most of the items involved (except some very high technology items related to power units larger than $500 \mathrm{MW}$, nuclear power plants, and other complex systems). These countries are grouped together in South 1. Of course, different countries in South 1 have different abilities. For example, India and China are practically self-reliant except for a few items, and even in a position to export, although at present these exports are at a very low level.

4. Medium and small countries. Nearly 30 developing countries of small to medium size have individually moderate requirements for energy capital goods. Together they represent $27 \%$ of the population, $24 \%$ of energy consumption, and $29 \%$ of electricity capacity of the developing countries. Some already partially manufacture low-, medium-, and occasionally high-technology items (and some export these products at small scale). If they wish to be more self-reliant, they may have to undertake joint ventures and cooperative agreements with other countries, or work through country groups, such as ASEAN and LAFTA. Countries of South 3, on the other hand, could produce at most lowtechnology items, and will continue to depend on imports.

5. Requirements of engineering services. Engineering services required for energy industries are for three levels of operations: (a) exploration, surveys, feasibility reports, and planning; $(b)$ layout and construction; and $(c)$ operating and maintenance. The first is the most difficult, requiring foreign help for even some of the South 1 countries. South 2 countries of ten require partial help for construction, and South 3 countries can barely manage to maintain and operate facilities.

6. Prognosis for country groups. As and when developing countries industrialize, their ability to manuf acture and export will increase, especially for low- and medium-technology items. Excluding a few items, it would be some time before even South 1 countries could fully meet their own needs and export high-technology items on a large scale. The price trends for these items also bear this out. For example, in 1967-1978 the prices of high-technology items increased five- to sixfold, but those of medium- and low-technology items only two- or threefold. Some of this pattern could be attributed to general inflation, but the rest could be explained to a large extent by the fact that there is more competition in low- and medium-technology items. Considerable price increases seem to have taken place during 1977-1978.

7. The shares of the main exporters of power equipment, namely the European Community, the United States, and Japan, in world exports are roughly $55 \%, 13 \%$, and $14 \%$, respectively. These shares have not changed much in the last decade, except for a Japanese rising share at the expense of the US share. In value terms, the industries showed annual growth of $18 \%$ in 1976-1980. 
8. North-South and South-South cooperation. Over the last two decades, the North has built up more capital goods manufacturing capacity than it needs in the present circumstances of high oil prices, which have led to conservation and hence to reduced energy consumption. In principle, in a cooperative world, the developing countries would not need to duplicate these efforts and could use this idle capacity. However, in practice, the prices of capital goods are increasing, compelling these countries to increase their own manufacturing, if they have the abilities and the critical size to do so. In a similar way the developing countries are increasing their search for domestic oil and building refineries, in spite of the present over-capacity in world oil production and refining. Countries of the North could cooperate directly with the countries of South 1, owing to the similar nature of their demand for capital goods (in terms of scale), especially in high-technology items. South 2 countries have moderate demands individually, but together they import more capital goods than South 1 countries; in 1978, 29 countries of South 2 spent nearly US\$1 2 billion compared to US\$6 billion by 7 countries of South 1. However, the energy capital goods industries in the North would require reorientation to cater to the demands of these countries, which would require items for smaller facilities than are prevalent in the North or South 1. South-South cooperation for low and mediumtechnology items will be most useful and is especially essential for South 3 , whose needs may not be met by the North (such as for small mines, small oil wells of a few tons per day capacity, or power plants of 100 $\mathrm{kW}$ to $5 \mathrm{MW}$ ).

9. New and renewable energy resources. New and renewable energy sources would require largely medium- and low-technology items (except for photovoltaic conversion and other complex systems), which could be rather easily produced by countries of South 2 and South 3 . However, each energy facility, such as a windmill, a small hydropower facility, or a bio-digester, requires individual attention, so that a large number of semiskilled persons may be required. This problem could be solved in the long run (and could even help solve the unemployment problem). Even so, capital goods for conventional commercial energy options would remain the major components of imports for the energy sector until at least the end of the century.

\section{ACKNOWLEDGMENTS}

Parts of this study have been funded by UNIDO and the European Commission. I am gratef ul for their permission to use their work. I am indebted to Mr. H. von Scholz of the EC and to Y. Cho, S. Park, C. Rademacher, and C. Gürkök of UNIDO for their encouragement and interest. I am 
grateful to the editors, Professors Harvey Brooks and Jack Hollander, for critically reviewing this chapter.

I am grateful to Lilo Roggenland for patiently typing the drafts of this manuscript.

\section{Literature Cited}

1. World Bank. 1980. Energy in Developing Countries. Washington, DC

2. United Nations. 1980. Yearbook of International Trade Statistics, Vol. 1, Trade by Country, Vol. II, Trade by Commodity

3. Jankowski, J. 1980. Industrial Energy Demand and Conservation in Developing Countries. Washington, DC: Resources for the Future

4. United Nations. 1981. Yearbook of World Energy, Production Data

5. Bangladesh: Annual Report of Electricity Board. 1983

6. Kenya. 1980. Fourth Five-Year Plan. Planning Commission, Nairobi

7. Government of India. 1981. Sixth FiveYear Plan 1980-85. New Delhi : Planning Commission

8. World Bank. 1983. Energy Transition in Developing Countries. Washington, DC

9. Parikh, J. 1982. Investment Requirements for Developing Power Industries for the Industrialization of Developing Countries. UNIDO/IS.359. Vienna

10. Parikh, J. 1984. Capital Goods for Energy Development. UNIDO/IS.457. Vienna

11. Parikh, J. 1982. Modeling Energy Demand for Policy Analysis. New Delhi: Planning Commission, Government of India

12. ESCAP. 1970. Thermal Power Stations: A Technoeconomic Study

13. Surrey, J. 1982. Trends in the Procurement of Electricity Generating Plant in Developing Countries. UNCTAD, TD/B/C.6/AC.9/3. Geneva

14. Kirtley, J. R., Tabors, R. D. 1984.
Analysis of the Electric Power Equipment Sector in Developing Counties. (Based on UNIDO Country Case Studies.) Cambridge, Mass : Meta Systems

15. Tiberghien, R., Vernet, P. 1984. The Production of Electric Power Equipment in the Developing Countries: A Typology of the Developing Countries and Elements of a Strategy. Grenoble, France: Inst. Recherche Econ. et de Planification du Dev. (IREP)

16. Erber, F. 1982. Technology Issues in the Capital Goods Sector: A Case Study of Leading Industrial Machinery Producers in Brazil. UNCTAD, TD/B/C.6/AC.7/6. Geneva, Switzerland

17. Smil, V. 1983. China's Energy Advances and Limitations. Mimeo

18. UNCTAD Secretariat. 1980. Energy Supplies for Developing CountriesIssues in Transfer and Development of Technologies. UNCTAD, TD/B/C.6/31/ Rev.1. Geneva, Switzerland

19. UNCTAD Secretariat in collaboration with Jin-joo Lee and $H$. N. Sharan. Technological Impact of the Public Procurement Policy: The Experience of the Power Plant Sector in the Republic of Korea. UNCTAD/TT/60. Geneva, Switzerland

20. UNCTAD Secretariat. 1982. The Energy Sector in Developing Countries: Issues in the Transfer, Application and Development of Technology. UNCTAD, TD/B/C.6/AC.9/2. Geneva, Switzerland

21. Bechtel Corporation. 1976. Availability of Selected Materials and Equipment Commodities for US Energy Development Program. Report No. E(49-1)-3794 


\section{APPENDIXES}

Appendix 1 Lists of countries for:

\begin{tabular}{lll}
\hline South 1 & \multicolumn{1}{c}{ South 2} & The remaining developing countries mentioned in the \\
\hline Argentina & Algeria & World Energy Statistics of the UN (1981) \\
Brazil & Angola & \\
China & Ghana & \\
India & Ivory Coast & \\
Mexico & Kenya & \\
Venezuela & Morocco & \\
Korea Rep. & Mozambique \\
& Nigeria \\
& Tunisia \\
& Zaire \\
& Egypt \\
& Iraq \\
& Syria \\
& Guatemala \\
& Chile \\
& Colombia \\
& Ecuador \\
& Peru \\
& Bangladesh \\
Indonesia \\
Iran \\
Korea Dem. Rep. \\
Malaysia \\
Pakistan \\
Philippines \\
Thailand \\
Hong Kong \\
Saudi Arabia \\
Turkey \\
\\
\end{tabular}


Appendix 2 Example of hierarchy of SITC classification used for trade of all items. In the following hierarchy of trade classification, at each successive digit, the disaggregation increases, keeping the first $n-1$ digit constant for $n$th digit level items. The following example will make it clear (it corresponds to revision 1)

SITC No. Description

One-digit level

$7 \quad$ All manufacturing

Two-digit level

77 Total electric machinery

Three-digit level

771 Nonelectric power-generating equipment (high technology):

nonelectric steam-generating boilers including related items such as superheaters, condensers, etc. Although steam boilers could be used in other industries as well, their percentage is expected to be small $(10 \%$ in the case of India)

772 Electric circuit apparatus

Four-digit level

7711 Steam boilers

7713 Steam turbines

7722 Switch gears 